\title{
Assessment of sensorimotor intelligence and psychomotor development in clinically healthy infants assisted in the public health sector
}

\author{
María F. Romero, B.S. ${ }^{a}$ Juan P. Copparoni, B.S. ${ }^{a}$, María V. Fasano, M.D. ${ }^{a}$, Marisa \\ Sala, M.D. ${ }^{a}$, Mariela Mansilla, M.D. ${ }^{a}$, Agustina Vericat, M.D. ${ }^{a}$ and \\ Liliana Disalvo, Biochemist ${ }^{a}$
}

\begin{abstract}
Introduction: Infancy is the period of greatest neuroplasticity. The early detection of developmental disorders helps to provide a timely intervention aimed at reducing sequelae and/or complications.

Objective: To assess psychomotor and cognitive development in infants between 6 and 9 months old assisted in the public health sector.

Population and methods: Descriptive study with follow-up of full-term infants who were clinically healthy at the time of assessment and had an adequate weight, height, and head circumference for their age. The AssessmentScale of Psychomotor Development and the Argentine Scale of Sensorimotor Intelligence were used in infants aged 6-9 months. Early stimulation was the intervention provided to those who showed a risk or delay. The prevalence of risk/delay of psychomotor development and sensorimotor intelligence was determined. The statistical software package R, version 3.3.1 was used.
\end{abstract}

Results: A total of 102 children were assessed. At 6 months old, $22.5 \%$ had a developmental risk/delay. The prevalence of unexpected results for age in psychomotor development and sensorimotor intelligence was $13.7 \%$ and $16.7 \%$, respectively. These children received early stimulation and all showed improved results. At 9 months old, the prevalence of risk/delay was $20.6 \%: 14.7 \%$ in psychomotor development and $9.8 \%$ in sensorimotor intelligence.

Conclusion: At 6 months old, $22.5 \%$ of infants had a developmental risk/delay; at 9 months old, this prevalence was $20.6 \%$. An early assessment of development helped to detect disorders and provide an early intervention.

Key words: infant development, cognition, developmental delay.

http:/ / dx.doi.org/10.5546/ aap.2019.eng.224

E-mail address:

María F. Romero, B.S.: romero.mflor@gmail.com

Funding:

SANCOR Cooperativas Unidas Limitada (C.U.L.).

Conflict of interest:

None.

Received: 4-24-2018

Accepted: 1-24-2019

\section{INTRODUCTION}

Infancy is a critical and vulnerable stage. It is considered the postnatal period of greatest neuroplasticity, during which breastfeeding and the bond generated through this practice will have immediate and mediate consequences on a child's optimal development. ${ }^{1}$

Infant development is a dynamic and continuous process for the progressive organization of biological, psychological, and sociocultural functions that combine in a complex interaction. It takes place from conception to maturity and is intimately related to the development of the nervous system. ${ }^{2}$ It is relevant to measure developmental disorders, especially in a critical and vulnerable period between 0 and 5 years old. ${ }^{3}$

Several instruments of varying complexity are useful to assess different aspects of neurodevelopment. For example, the Assessment Scale of Psychomotor Development (Escala de Evaluación del Desarrollo Psicomotor, EEDP), a qualitative-quantitative development screening instrument for children aged 0-24 months that allows to establish a development coefficient. The EEDP assesses, in an objective, valid, and reliable manner, infant performance in situations that require a certain level of psychomotor development for resolution. ${ }^{4}$

The Argentine Scale of Sensorimotor Intelligence (Escala Argentina de Inteligencia Sensorio motriz, EAIS) is used to assess sensorimotor intelligence in children aged 6-24 months, thus allowing to detect 
cognitive alterations. The EAIS has standard reference values for the Argentine population. ${ }^{5}$

In our region, few studies have been published on the prevalence of developmental delay in "apparently healthy" children. Schapira and Oiberman have proposed that "both instruments may be considered complementary and essential because they provide a comprehensive child assessment". ${ }^{6,7}$

Although some publications used one instrument or the other, there were no studies that had used both in a clinically healthy population.

In this study, the use of both the EEDP and the EAIS has allowed us to assess different child development aspects, thus favoring a comprehensive perspective of children and the early detection of disorders in one or more areas of development. This view promotes a timely intervention and the prevention of long-term negative consequences.

The objective of this study was to assess psychomotor development and sensorimotor intelligence in infants at 6 and 9 months old assisted in the public health sector.

\section{POPULATION AND METHODS}

Infants were assessed at 6 and 9 months old among those who attended a pediatric health checkup at the Health Observatory of the Pediatric Research and Development Institute (Instituto de Desarrollo e Investigaciones Pediátricas, IDIP), Hospital Sor María Ludovica, between March and December 2011.

\section{Design}

This was an observational, descriptive follow-up study. Infants aged 6 months, who had been born at term (between 37 and 41 weeks of gestation) and had an adequate weight, height, and head circumference for age and whose parents had agreed to participate in the study and had signed the informed consent were included.

Infants who had an ongoing disease, a genetic disorder or a chronic condition, who had had a central nervous system disease, or who had a low birth weight were excluded.

The sample was purposively selected. All infants who met the inclusion criteria were included and were seen between March and December 2011. Assuming a $20 \%$ prevalence of developmental disorders, ${ }^{8,9}$ the sample size was calculated to estimate the prevalence of developmental disorders in infants aged 6-9 months, with a $95 \%$ confidence and a
0.07 error. The number was estimated at 126 infants, which was finally adjusted for a $15 \%$ potential loss to follow-up, thus establishing that 145 infants had to be enrolled.

Psychomotor development, defined as the progressive and orderly acquisition of functional skills during growth, was assessed using the EEDP, which examined the social, language, coordination, and motor areas. ${ }^{4-10}$

This test generated development coefficients (DCs) that were classified in the following categories:

Greater than or equal to 0.85: normal.

Between 0.84 and 0.7: risk.

Lower than or equal to 0.69: delay.

Sensorimotor intelligence, defined by J. Piaget as the ability to solve problems based on activities that involved, above all, perception, attitudes (tone), and movements without symbolic evocation (before language development), ${ }_{1}^{11}$ was assessed using the EAIS, which generated the following categories:

Percentile between the $50^{\text {th }}$ and the $100^{\text {th }}$ : normal.

Percentile above the $10^{\text {th }}$ and below the $50^{\text {th }}$ : risk.

$10^{\text {th }}$ percentile or below: delay.

In addition, the following sociodemographic data were recorded: parental age, level of education, employment status, and obstetric history.

\section{Ethical considerations}

The study was approved by the Institutional Research Protocol Review Committee (Comité Institucional de Revisión de Protocolos de Investigación, CIRPI) of Hospital de Niños Sor María Ludovica in March 2011.

\section{Statistical analysis}

Collected data were analyzed using the statistical software package $R$, version 3.3.1. The prevalence of risk/delay of psychomotor development and sensorimotor intelligence was determined. Qualitative outcome measures were reported as percentage (frequency), whereas quantitative outcome measures, as median (interquartile range [IQR]). The prevalence of unexpected results for age in both instruments was described with its corresponding $95 \%$ confidence interval (CI).

\section{RESULTS}

Initially, 140 infants aged 6 months were included in the study; however, 38 infants were 
excluded from follow-up for different reasons, so the final sample was made up of 102 infants. All families who were invited to be in the study protocol agreed to participate.

Infants who were included had been born at term from an uncomplicated pregnancy. Among fathers, $8 \%$ (8) were unemployed and $71 \%$ (72) had an informal employment relationship; $70 \%$ (71) of mothers were homemakers. Table 1 shows the general sociodemographic characteristics.

At 6 months old, $22.5 \%$ (23) of infants had a developmental risk/delay. The prevalence of unexpected results for age as per the EEDP and the EAIS was $13.7 \%(7.0 \%, 20.4 \%)$ and $16.7 \%$ $(9.4 \%, 23.9 \%)$, respectively. Among infants who had a poor score, $34.7 \%(8 / 23)$ failed both tests.

Regardless of the overall results in the EEDP, at 6 months old, the language area was the most affected one (Table 2 ).

Among the 23 infants who received stimulation and were reassessed at 9 months old, $84 \%$ (19) showed normal results in the second EEDP assessment and $16 \%$ (4) showed a risk; none had a delay. Likewise, $79 \%$ (18) had normal results in the second EAIS assessment and $21 \%$ (5) had a risk; none resulted in a delay.

TABLE 1. Sample characteristics. N: 102

\begin{tabular}{lc}
\hline Outcome measure & $\begin{array}{c}\text { Median (IQR) } \\
\text { N (\%) }\end{array}$ \\
\hline Sex (F) & $54(53)$ \\
Gestational age (weeks) & 39 \\
& $(38-40)$ \\
Birth weight (g) & 3300 \\
& $(2500-4000)$ \\
Head circumference at 6 months old (cm) & 42 \\
Weight at 6 months old (g) & $(39-48)$ \\
& 7620 \\
Height at 6 months old (cm) & $(5400-10970)$ \\
Maternal age (years old) & 65 \\
Paternal age (years old) & $(51-89)$ \\
Maternal level of education & $24(21-30)$ \\
(incomplete secondary education) & $29(23-34)$ \\
Paternal level of education & \\
(incomplete secondary education) & $65(64)$ \\
Exclusive breastfeeding at 6 months old & $44(43)$ \\
Type of delivery (vaginal) & $72(71)$ \\
Co-sleeping & $48(47)$ \\
\hline
\end{tabular}

IQR: interquartile range.
At 9 months old, the prevalence of risk / delay was $20.6 \% ; 14.7 \%(7.8 \%, 21.6 \%)$ corresponded to the EEDP and $9.8 \%(4.0 \%, 15.6 \%)$ to the EAIS.

Among infants who had a poor score in the first psychomotor development assessment, $88 \%$ had results that were as expected in the second assessment. However, $12 \%$ had a risk score. In relation to infants who, at 6 months old, had a risk score, $77 \%$ had results that were as expected for their chronological age in the second assessment; $23 \%$ remained at risk, and the only infant who had a delay according to the EEDP showed a risk in the second assessment (Table 3).

Among infants who had a normal score in the sensorimotor intelligence test at 6 months old, $94 \%$ had again results that were as expected at 9 months old, whereas $6 \%$ of those whose results were as expected for their age at 6 months old in the EAIS showed a risk $(4 \%)$ or delay $(2 \%)$ in the second assessment. These infants did not receive an early stimulation intervention between the first and the second assessment (Table 3).

A total of $21 \%$ (21) of infants were referred for early stimulation in the second assessment, $81 \%$ (17) of these had had "normal" results in the first assessment.

\section{DISCUSSION}

The most significant finding of this study was that the overall observation of development in a sample of clinically healthy infants at 6 months old attending a health checkup and assessed using two tests (EEDP and EAIS) showed that $22.5 \%(n=23)$ of infants had signs of psychomotor development or sensorimotor intelligence alterations. Of these, 17 had a delay; and 8 of them failed both tests.

Unlike Bermúdez and Carabajal, ${ }^{8}$ who used the EEDP and found a $22.8 \%$ risk/delay in the 7-12-month-old age group, in our infants, the risk/delay accounted for $14.7 \%$. In that study, 559 infants and toddlers aged 0-24 months were assessed and a half-year comparison was done;

TABle 2. Results of the Assessment Scale of Psychomotor Development by area at 6 months old. N: 102

\begin{tabular}{lcc}
\hline Areas & \multicolumn{2}{c}{$\begin{array}{c}\text { Not normal } \\
\text { Percentage and number of cases }\end{array}$} \\
\hline Language & $13 \%(13), \quad$ IC $95 \%: 6.3 \% ; 19.2 \%$ \\
Motor & $6 \%(6), \quad$ IC $95 \%: 1.3 \% ; 10.4 \%$ \\
Coordination & $5 \%(5), \quad$ IC $95 \%: 0.7 \% ; 9.1 \%$ \\
Social & $5 \%(5), \quad$ IC $95 \%: 0.7 \% ; 9.1 \%$ \\
\hline
\end{tabular}

CI: confidence interval. 
both populations corresponded to samples made up of families who attended the public health care system. Lejarraga et al., ${ }^{9}$ used the National Screening Test (Prueba Nacional de Pesquisa, PRUNAPE) and found a $20 \%$ developmental delay; the authors assessed a population of children aged 0-6 years who had different socioeconomic levels. When analyzing toddlers who were between 12 and 24 months old and had a low socioeconomic level, the authors' findings were similar to those of Bermúdez and Carabajal. ${ }^{8}$

As reflected by results, in our study, there was a lower prevalence of risk or delay. Although it would be adventurous to take a guess, it should be considered that infants in our study belonged to a population with access to health services and that had embraced health care behavioral patterns; children are periodically taken for a pediatric health checkup and comply with their immunization schedule. In addition, it is also worth considering that screening instruments have a lower sensitivity when assessing children in this age group.

In this study, $13.7 \%$ of infants at 6 months old had a risk/delay as per the EAIS. Oiberman et al. ${ }^{7-12}$ found, in the Argentine population, a prevalence of risk or delay of $27.75 \%$ with the EAIS (14 \% of risk and $13.75 \%$ of delay); a priori, this was higher than the prevalence observed in our sample and this may be explained by the sample size of our study. However, the findings of Oiberman et al. were not divided by age and did not specify the prevalence at 6 months old. Besides, their sample was made up of infants and toddlers aged 6-30 months, but included a scarce number of infants who were 6 to 9 months old (34 participants were 6 months and 36, 9 months).

It should be taken into consideration that our findings regarding a risk or delay prevalence at 9 months old are not comparable to the results by Bermúdez or Oiberman, because, in our study, infants with a risk or delay at 6 months old received an intervention. Likewise, it cannot be compared to a more recent study conducted in Chile that used the EEDP to assess infants and toddlers aged 8-24 months with a low socioeconomic level and found a $28.9 \%$ of risk/ delay. ${ }^{13}$

International publications, like the one by Q. Wei et al., ${ }^{14}$ found that $39.7 \%$ of infants and toddlers younger than 3 years had a developmental delay in at least one of the five areas. They concluded that there was a high prevalence of developmental delay in infants and toddlers younger than 3 years in poverty-stricken areas of China and proposed to implement an early detection and management program to approach this problem.

A weakness of our study was that our sample was homogeneous in terms of socioeconomic characteristics, which prevented us from establishing significant relations between psychomotor development or sensorimotor intelligence and parental level of education, maternal age, etc. Other factors were not assessed either, like the presence of anemia and micronutrient deficiency, especially iron, whose negative impact on psychomotor abilities has been widely documented. ${ }^{15,16}$

Among the infants who received early stimulation at 6 months old, $83 \%$ showed results according to what was expected for their age, whereas the remaining $17 \%$ improved their performance, in spite of having results that were not expected for their age. Although there was a trend towards a favorable course after the early stimulation intervention, this was not considered scientific evidence on the usefulness of this type of intervention. Future studies are required to investigate this subject matter.

TABLE 3. Results of the Assessment Scale of Psychomotor Development and the Argentine Scale of Sensorimotor Intelligence at 9 months old compared to the results obtained at 6 months old. N: 102

\begin{tabular}{lcccc}
\hline & & Second assessment \\
Risk & Normal & N (\%) & $\begin{array}{c}\text { Delay } \\
\text { N (\%) }\end{array}$ \\
\hline EEDP, first assessment & & $\mathbf{N}(\%)$ & $11(12)$ & 0 \\
& Normal & $77(88)$ & $3(23)$ & 0 \\
EAIS, first assessment & Risk & $10(77)$ & $1(100)$ & 0 \\
& Delay & 0 & $3(4)$ & $2(2)$ \\
& Normal & $80(94)$ & $5(29)$ & 0 \\
\hline
\end{tabular}

EEDP: Assessment Scale of Psychomotor Development; EAIS: Argentine Scale of Sensorimotor Intelligence. 
Based on an international review, a study by Walker et al. showed that psychosocial stimulation was beneficial for the development of malnourished children. ${ }^{17}$ In this study, children who received early stimulation for 2 years improved their performance. In turn, Moreno Mora et al. have demonstrated the effectiveness of a comprehensive stimulation program for lowweight children with developmental delay, which evidenced the trend towards a favorable course. ${ }^{18}$

Given that development is a dynamic process for the acquisition of different, increasingly complex abilities, the aspects assessed at 9 months old are not the same as the ones assessed before. This means that an infant that, at 6 months old, had a good score in any instrument used and whose results at 9 months old were not as expected, was not able to develop new abilities in stages that are subsequent to those assessed before.

Since, at 6 and 9 months old, a considerable number of clinically healthy infants were referred for early stimulation and that this population was not assessed in terms of development during their routine health checkup, it is important to implement actions aimed at detecting psychomotor development and sensorimotor intelligence alterations, providing a comprehensive perspective of children, and finding signs or evidence of disorders.

\section{CONCLUSIONS}

In this population, $22.5 \%$ of clinically healthy infants showed a risk/delay of psychomotor and cognitive development at 6 months old in at least one of the tests. The prevalence at 9 months old was higher than expected for the age.

An early assessment of infant development helped to detect developmental disorders and provide an early intervention.

\section{REFERENCES}

1. Cardoso MA, Hure AJ. Nutrition in the first 500 days of life. Public Health Nutr. 2014; 17(9):1907-8.

2. Cafiero PJ. Desarrollo Infantil y sus alteraciones. In: Sociedad Argentina de Pediatría. Pronap. 2008; 1:62-3.

3. Lejarraga H, Kelmansky D, Passcucci M, Masautis A, et. al. Evaluación del desarrollo psicomotor del niño en grupos de población como indicador positivo de salud. Arch Argent Pediatr. 2016; 114(1):23-9.

4. Rodríguez S, Arancibia V, Undurraga C. Escala de evaluación del desarrollo psicomotor: 0 a 24 meses. 12.a ed. Santiago de Chile: Galdoc; 1996.

5. Oiberman A, Mansilla M, Orellana L. Métodos y resultados. In: Nacer y Pensar Construcción de la Escala Argentina de la Inteligencia sensorio Motriz (EAIS) de 6 meses a 2 años. Vol I. Buenos Aires: CIIPME-CONICET; 2002.p.20-5.

6. Schapira IT. Comentarios y aportes sobre desarrollo e inteligencia sensorio-motriz en lactantes. Análisis de herramientas de evaluación de uso frecuente. Actualización bibliográfica. Rev Hosp Mater Infant Ramón Sardá. 2007; 26(1):21-7.

7. Oiberman A, Mansilla M, Orellana L. Evaluación de la inteligencia en bebés argentinos: Escala Argentina de Inteligencia Sensoriomotriz. Arch Argent Pediatr. 2006; 104(4):316-23.

8. Bermúdez E, Carabajal N. Evaluación del Desarrollo Psicomotriz en niños de 0 a 24 meses. Arch Argent Pediatr. 1995; 93(6):354-62.

9. Lejarraga H, Menéndez A, Menzano E, Guerra L, et al. Screening for developmental problems at primary care level: a field programme in San Isidro, Argentina. Paediatr Perinat Epidemiol. 2008; 22(2):180-7.

10. Lejarraga H. Desarrollo del niño en contexto. Buenos Aires: Paidós; 2006.

11. PiagetJ.El nacimiento de la inteligencia en el niño. Ginebra: Neuschatel Delachaux et Niestlé; 1973.

12. Oiberman A, Paolini C, Mansilla M. Escala Argentina de Inteligencia Sensorio Motriz. Percentiles Nacionales. Interdisciplinaria. 2012; 29(2):305-23.

13. Santelices Álvarez M, Besoain C, Escobar M. Monoparentalidad, trabajo materno y desarrollo psicomotor infantil: Un estudio chilenoen niños que asisten a salas cuna en contexto de pobreza. Univ Psychol. 2015; 14(2):675-84.

14. WeiQ, Zhang J, Scherpbier R, Zhao C, et al. High prevalence of developmental delay among children under three years of age in poverty-stricken areas of China. Public Health. 2015; 129(12):1610-7.

15. Carter RC, Jacobson JL, Burden MJ, Armony-Sivan R, et al. Iron deficiency anemia and cognitive function in infancy. Pediatrics. 2010; 126(2):e427-34.

16. Lozoff B, Smith J, Kaciroti N, Clark K, et al. Functional significance of early-life iron deficiency: outcomes at 25 years. J Pediatr. 2013; 163(5):1260-6.

17. Walker SP, Chang S, Powell CA, Baker-HenninghamH. Building human capacity through early childhood intervention: The Child Development Research programme at the Tropical Medicine Research Institute, The University of the West Indies, Kingston, Jamaica. West Indian Med J. 2012; 61(4):316-22.

18. MorenoMora R, Pérez Díaz C. Retardoen el neurodesarrollo en niños de la Habana Vieja". Rev Cubana Med Gen Integr. 2008;24(3) [Accessed on: January $28^{\text {th }}, 2019$ ]. Available at: http:/ / scielo.sld.cu/pdf/mgi/v24n3/mgi12308.pdf. 